\title{
Process System Engineering for Sustainability in Asia Pacific
}

\author{
Denny K. S. $\mathrm{Ng}^{1} \cdot$ Richard Lakerveld ${ }^{2}$ \\ Published online: 21 February 2019 \\ (C) Springer Nature Singapore Pte Ltd. 2019
}

The theme of this special issue is "Process System Engineering for Sustainability in Asia Pacific." A total of ten papers including a review paper were accepted for publication after the peer review process in this special issue. These papers were contributed mostly by outstanding research groups from various Asia Pacific countries, namely, India, the Philippines, Hong Kong, Portugal, and Malaysia. In this special issue, a review paper on Lean and Green Manufacturing is presented. Meanwhile, the other papers may be broadly categorized in two general aspects, i.e., optimization and assessment of energy industry and biomass industry. A brief review of these papers is given as follows:

\section{Review paper on Lean and Green Manufacturing}

In this review paper (Leong et al. 2019), the origin development and contribution of lean manufacturing and green manufacturing are first explored. Based on the literature review, there is no proper definition for lean and green. Therefore, Leong et al. (2019) explored the application and impact of lean and green approach in the manufacturing industry to promote sustainable manufacturing. Similarities and benefit of both lean and green approaches are identified and implementation strategies are presented.

\section{Papers on Energy Industry}

Five papers in the Special Issue cover the developments of advanced energy systems. These include optimization of

Denny K. S. Ng

Denny.Ng@hw.ac.uk

Richard Lakerveld

r.lakerveld@ust.hk

1 School of Engineering and Physical Sciences, Heriot-Watt University Malaysia, Putrajaya, Malaysia

2 Department of Chemical and Biological Engineering, Hong Kong University of Science and Technology, Clear Water Bay, Kowloon, Hong Kong polygeneration system (Ray and De 2019), critical analysis of biomass tri-generation systems (Andiappan et al. 2019), modeling of solar and biomass hybrid power generation (Suresh et al. 2019), optimization of oxy-combustion, and gasification power plant (Wang et al. 2019) as well as assessment of energy end-use technologies in India's households (Kumar Singh et al. 2019).

India is an economic powerhouse in the Asian-Pacific Region with a fast-growing energy demand. The current transition towards sustainable energy offers important opportunities for this region. This Special Issue features three papers on the subject of sustainable energy in India. Ray and De (2019) study the impact of modern energy-efficient technologies in India. Their focus is on the generation of various forms of energy from various inputs. In particular, an optimization method is developed for a polygeneration system that has renewable sources such as solar, biomass, and wind as an input and electricity and chemicals as an output. A case study shows how the method can be used to lower electricity costs for a village located in India. Kumar Singh et al. (2019) presents a comprehensive framework for an economic inputoutput model including lifecycle assessment. A data-driven analysis shows how such a multi-perspective approach can predict the impact of investments in various energy-efficient appliances in India's residential sector. Intermittence of renewable energy sources such as solar and wind is often a challenge. Suresh et al. (2019) recognizes the importance of solar power plants for India, which urges new approaches to solve the intermittence problem. They present a case study of a solar power plant that is combined with biofuels to achieve a stable power generation from renewable energy sources. The results demonstrate the viability and stability of such system.

Energy systems are getting increasingly more complicated due to tighter integration of various components. In order to optimize the energy system as a whole, model reduction methods are often needed. Wang et al. (2019) presents a model reduction method that allows for the simultaneous optimization of an air separation unit and a gas turbine in an integratedgasification-combined-cycle (IGCC) power plant. The 
integrated method has clear benefits compared to the optimization of standalone units.

As most of the energy systems are highly integrated, therefore, in any event of disturbance, the rippling effects will cascade to the entire system. In order to reduce the impact of disturbances, it is often needed to allocate redundant process units or on standby for an entire system. Such strategy demands high capital investment. Therefore, in order to address this issue, Andiappan et al. (2019) present a framework to identify the most critical process unit in the system prior to allocating equipment redundancy. The proposed framework is applied in a tri-generation system.

\section{Papers on Biomass Industry}

Four papers in this special issue addressed various issues related to biomass industry. Ngan et al. (2019) used analytic network process (ANP) approach to assess, evaluate, and prioritize risks commonly associated with the oil palm biomass industry. Lai et al. (2019) presented a framework for decision-making involved in the overall chemical product design and production process. Pahija et al. (2019) revised the population balance equation (PBE) to evaluate the population growth, birth, death, and division of microalgae. On the other hand, a novel debottlenecking approach which incorporates principal component analysis (PCA) can be used to identify sustainability bottlenecks in integrated biomass supply chain. Next, debottlenecking strategies are presented.

To promote sustainable development, economic, environment, and society aspects have to be taken into consideration simultaneously. In Malaysia, several policies and strategies have been formulated to promote green growth to achieve sustainable production and consumption. However, the green industry still faces significant challenges, hindering progress towards sustainable development. In order to prioritize the risk of each aspects, Ngan et al. (2019) adapted ANP approach which used in multi-criteria decision analysis to address the sustainable development of Malaysian oil palm biomass industry.

Based on the current available technologies, biomass can be converted into a wide spectrum of products. Furthermore, consumer-driven chemical product design has gained magnificent attention in chemical industry, owing to the shifting of market from commodity products to high-value-added products. Therefore, chemical product design has shifted from chemist into process a multi-faceted process that requires collective efforts from various fields. Lai et al. (2019) presented a framework to facilitate the decision-making involved in the overall chemical product design and production process by integrating four major organizational units of an enterprise.

Processes involving particles are plentiful throughout chemical industry. The intrinsic properties of particles such as size and shape may be subject to change during processing. Population balances have been used for decades to describe the dynamic development of the intrinsic properties of particles. However, the numerical solution of the resulting partial differential equation remains challenging, especially when the model is used for optimization or control purposes and when various physical phenomena such as breakage, growth, agglomeration, and nucleation occur simultaneously. Pahija et al. (2019) propose a modified population balance equation such that the numerical solution of the population balance becomes more stable and accurate compared to traditional methods. The method is illustrated for the simulation of microalgae growth, which has important implications for the sustainable production of fuels and chemicals.

Within the sustainable development process, it is often to encounter bottlenecks that can be in the form of economic, environmental, or social dimensions. In order to improve the sustainability of an industry, such sustainable bottlenecks need to be removed. Viewing the importance of such issue, How and Lam (2019) proposed a systematic framework based on PCA to identify the sustainable bottlenecks within an integrated biomass supply chain. Debottlenecking strategies were also presented to overcome the limitations within the supply chain.

Acknowledgments The editors would like to acknowledge the excellent support of Desthinie Jane K. Jarandilla in managing this special issue. Efforts for peer reviewing from all reviewers are greatly appreciated. This ensures a high-quality special issue to be delivered.

Publisher's Note Springer Nature remains neutral with regard to jurisdictional claims in published maps and institutional affiliations.

\section{References}

Andiappan, V., Benjamin M. F., Tan, R. R. and Ng, D. K. S. (2019). An integrated framework to address criticality in biomass tri-generation systems via redundancy allocation, process integration and optimization for sustainability

How, B. S. and Lam, H.L. (2019). PCA method for debottlenecking of sustainability performance in integrated biomass supply chain, process integration and optimization for sustainability

Kumar Singh, V., Henriques, C. O. and Martins, A. G., (2019). A multiperspective assessment of best available energy end-use technologies in India's households, process integration and optimization for sustainability

Lai, Y. Y., Chu, K. H. Y., Hau, H. P., Chow, C. P. and Chmmangattuvalappil, N. (2019), Enterprise decision-making framework for chemical product design in integrated biorefineries, process integration and optimization for sustainability,

Leong, W. D., Lam, H. L., Ng, W. P. Q., Lim, C. H., Tan, C. P. and Ponnambalam, S. G., (2019). Lean and green manufacturing - a review on its applications and impacts, process integration and optimization for sustainability

Ngan, S. L., Promentill, M. A. B., Yatim, P. and Lam, H. L. (2019). A novel risk assessment model for green finance: the case of 
Malaysian oil palm biomass industry, process integration and optimization for sustainability

Pahija, E., Lee, P. Y. and Hui, C.-W. (2019). A revision of population balance equation applied to microalgae with birth, growth, and death, process integration and optimization for sustainability, DOI

Ray, A. and De, S. (2019). Polygeneration using renewable resources: cost optimization using linear programming, process integration and optimization for sustainability, DOI
Suresh, N. S., Thirumalai, N. C. and Desappa, S. (2019). Modeling of solar and biomass hybrid power generation - a techno-economic case study, process integration and optimization for sustainability, DOI

Wang, M., Liu, Q., Liang, Y., Hui, C. W. and Liu, G. (2019). Reduced integration optimization model for coupled elevated-pressure air separation unit and gas turbine in oxy-combustion and gasification power plant, process integration and optimization for sustainability, DOI 